\title{
BMJ Global Health Reframing the impact of business on health: the interface of corporate, commercial, political and social determinants of health
}

\author{
Connor Rochford, ${ }^{\oplus 1}$ Naveen Tenneti, ${ }^{2}$ Rob Moodie ${ }^{3}$
}

\begin{abstract}
To cite: Rochford C, Tenneti N, Moodie R. Reframing the impact of business on health: the interface of corporate, commercial, political and social determinants of health. BMJ Global Health 2019:4:e001510. doi:10.1136/ bmjgh-2019-001510
\end{abstract}

Handling editor Seye Abimbola

Received 15 February 2019 Revised 30 April 2019 Accepted 4 May 2019

Check for updates

(C) Author(s) (or their employer(s)) 2019. Re-use permitted under CC BY-NC. No commercial re-use. See rights and permissions. Published by BMJ.

${ }^{1}$ Blavatnik School of Government, University of Oxford, 0xford, UK

${ }^{2}$ Nossal Institute for Global Health, University of Melbourne, Melbourne, Victoria, Australia ${ }^{3}$ School of Population and Global Health, University of Melbourne, Melbourne, Victoria, Australia

Correspondence to Dr Connor Rochford; connor.rochford@bsg.ox.ac.uk

\section{INTRODUCTION}

In January 2018, three of the world's largest companies-Amazon, Berkshire Hathaway and JPMorgan Chase (ABC)-announced their intention to form a healthcare company for their employees in the USA. ${ }^{1}$ The partnership, led by the well-known surgeon and writer Atul Gawande, intends to develop new methods to improve care for the 1.2 million employees who receive health insurance from these firms. If successful, the innovations could diffuse through to the 150 million other Americans currently receiving health insurance through their employers. ${ }^{1}$ This move occurs on the background of decreasing public financing for healthcare and increasing service competition with the private sector, ostensibly to improve efficiency. ${ }^{2}$ The design of $\mathrm{ABC}$ is also shaped by its need to interact with the US healthcare system-one of the least effective examples in the OECD—which former UN boss Ban Ki-moon has diagnosed as 'morally wrong'.

Considering the impact of business on health more broadly requires reconciling such an initiative with the other practisesboth health promoting and detracting-of these corporations. For example, in August 2018, Amazon released figures from its UK corporation tax bill, which recorded tax payments of 4.5 million pounds on profits of 72 million pounds. ${ }^{4}$ While the various loopholes available in domestic and international law ensure that this is not technically a crime, this figure is significantly less than the nominated corporate tax rate of $21 \%$ for companies with annual profits exceeding 300 000 pounds, and is certainly not a victimless practice. ${ }^{5}$

The case raises several questions and opportunities for academic inquiry, which are as follows:

\section{Summary box}

The current approach to assessing the role of the for-profit sector in health is too narrow, fails to consider the varied activities of the diverse constellation of private companies, and there has been some, albeit limited, work done to empirically evaluate their impact.

- Existing approaches rarely articulate a positive vision or actions for business, lack the necessary specificity required to hold individuals to account and may alienate important actors through a persistently negative approach.

- A reframed and expanded inquiry that includes the type of organisation and reviews the internal processes (eg, employee relations and physical infrastructure) and external processes (eg, product and/ or service delivery and lobbying) could strengthen efforts to manage the responsibility of business for health, which will require combining existing academic endeavours concerning the corporate, commercial, social and political determinants of health.

- Possible advantages of a reframed model include guidance of empirical research, strengthened advocacy efforts and an improved ability to work across sectors; ultimately, this will also help health professionals to be much clearer in determining if and when they should or should not be entering into partnerships with for-profit entities.

1. In times of increasing austerity, what range of important public services could have been funded with this foregone tax?

2. Alternatively, how could this profit have been used to invest in the health and well-being of employees and their families?

3. And, what responsibilities does Dr Gawande-or, for that matter, the respective CEOs, Jeff Bezos, Warren Buffet and Jamie Dimon-have for the health of their employees, and that of the individuals that interact with or are impacted by their business? 
Existing frameworks assessing the role of business in health do not empower health professionals to answer such questions. ${ }^{6} 7$ This is in part because the predominant focus of current analytical efforts is on the external services or products delivered by private entities, without an appreciation for the way that the internal processes (ie, employee relations, workplace design and physical infrastructure) and external processes (eg, sales, marketing and lobbying) affect the operation of power between different stakeholders and influence health. Further, critique often focuses rightly on diagnosing systemic ills, but then fails to extend this analysis to a constructive dialogue that proposes a viable response for business, both as collective agents and individual actors. A much more nuanced assessment of the relationship between business and health is urgently needed.

Responding to this need, this article will propose a new, comprehensive framework for describing, assessing and responding to the role of corporate power and influence over health risks, outcomes and systems.

\section{AN UNEVEN CONTEST}

Supranational companies (ie, those that are above the nation state) have enormous and unprecedented influence over the lives of consumers and citizens. At last count, 71 of the worlds largest 100 economies are corporations. ${ }^{8}$ These influences can be direct (ie, the power to shape people's choices and behaviours) and indirect (ie, propagating particular political and economic models). McKee and Stuckler posit that this influence (or power) that corporations wield is central to the "extremely complex subject' of their impact on health. ${ }^{9}$ The scale of this power has at times rendered 'traditional' public health levers of regulation and taxation ineffective in responding to the contemporary methods of business. Others have reverse engineered corporate techniques, for example, in a recent call for the health community to develop forms of 'social lobbying' with the intention of 'influencing decisions made by governments, solely to protect and further the greater social good, including health'. ${ }^{10}$

However, it is naive to ignore the reality of the global political economy, whereby some businesses actively work against population health by virtue of their products or when it threatens their political and economic interests. ${ }^{11}$ The financial might of so many of the megacorporations-and the political and social influences they purchase-ensures that public health advocates will never be able to fight fire with fire. Notwithstanding enhanced political and policy engagement, strengthened academic analysis could contribute to addressing business influence and improving health outcomes.

\section{THE STATUS QUO: FENSA AND THE CORPORATE/COMMERCIAL DETERMINANTS OF HEALTH}

Efforts to examine the role of business in health are neither new nor without controversy. The Global Fund attracted attention in 2018 when it commenced, and then rapidly withdrew from, a partnership with the global alcoholic beverage company, Heineken. ${ }^{12}$ Many were also surprised when Derek Yach, a key protagonist in the development of the Framework Convention for Tobacco Control, was appointed to lead a Philip Morris International funded antismoking initiative, diagnosing the initiative as 'not credible'. ${ }^{13}$ While some cases may appear black and white, there are many past, existing and proposed future relationships that involve greater complexity.

The need to carefully navigate public-private relationships was formally recognised in 1993, when the World Health Assembly called on the WHO to 'mobilise and encourage the support of all partners in health development, including non-governmental organisations and institutions in the private sector'. ${ }^{14}$ The latest iteration of the WHO's thinking is embodied in the Framework of Engagement with Non-State Actors (FENSA), which describes the different forms of potential interaction between the WHO and business (eg, technical collaboration, financial support, and so on) and discusses their risks and benefits. ${ }^{15}$ However, FENSA provides no such guidance on how other health system actors should approach business. Further, FENSA is explicitly focused on relationships and does not provide any tools or frameworks for evaluating businesses and their heterogeneous impacts on health.

While this analysis is focused on conceptual frameworks for understanding the role of business in health, it is important to understand the breadth of the existing literature. Current academic analyses of the role of business can be categorised into a 'general' literature, focused on the overall impact of business on health (eg, see descriptions of Kickbusch et al and Millar's work ${ }^{67}$ ), and 'industry-specific' literature that considers businesses or clusters of businesses (eg, see Miller and Harkins work on food and alcohol industry lobbying ${ }^{16}$ ) and their impact on health. This literature can be further sub-divided into descriptions of how businesses exercise this impactwhether through evaluation of general strategies or more thorough descriptions of specific approaches or issues (eg, work by Buse and Waxman on public-private partnerships $\left.{ }^{14}\right)$.

We focus on two key frameworks that have helped to formalise understanding of how businesses impact on health: the corporate determinants of health (CorDOH) and the commercial determinants of health (ComDOH). These will together be referred to as $\mathrm{CDOH}$ (see figure 1 'The status quo' for a schematic representation). Millar, in outlining the CorDOH, recognised the varied and significant impacts that corporations could have on 'population health, health inequities and healthcare expenditures' ${ }^{6}$ He noted that while some companies embraced a triple bottom line-'people, planet and profits'-others used the language of corporate social responsibility or creating shared value to disguise their negative impacts. The $\mathrm{ComDOH}$ are defined as 'strategies and approaches used 


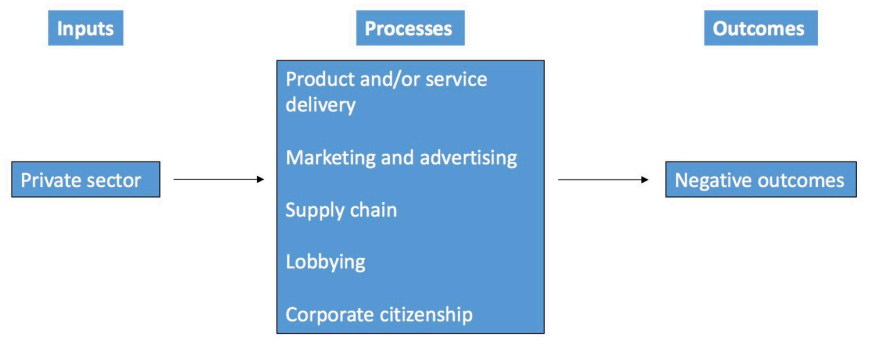

Figure 1 The status quo.

by the private sector to promote products and choices that are detrimental to health'. ${ }^{7}$ These approaches are embedded in the 'processes' box of figure 1 .

There are two main limitations with these academic frameworks.

First, the private sector is conceptualised as a homogenous space, with limited recognition of the almost boundless variety of entities, products, scale, and economic and political influence. While the CorDOH may recognise some differences in impact, there is no analysis of the underlying institutional structures and how these may contribute to or restrict negative impact. Analysis focuses on activities conducted by businesses, including product delivery, supply chain management and lobbying ('external processes'), while failing to engage in any discussion of internal processes of businesses-including employee relations and infrastructure managementand how these might influence health.

Second, the status quo almost exclusively links these business processes to adverse outcomes. The ComDOH employs an explicitly negative framing that ignores the traditional understanding of 'determinants' as factors that have a spectrum of effects. The discussion of CorDOH is slightly more nuanced, with a recognition that some companies may embrace a 'triple bottom line' in their approach to business. ${ }^{6}$ However, application of this framework has generally been limited to discussions of the harmful impacts of business on health. The narrow and negative focus on malign influences and strategies to mitigate its effect inherent in the existing literature inhibits our understanding of business influence on health and creates a tension between existing research on $\mathrm{CDOH}$ and the desire-in some circles-for more meaningful engagement by the different for-profit enterprises. It also constantly pits public health as being inherently against the private sector-this is both untrue and a grave tactical error with respect to gaining a greater societal understanding of public health's role.

There is a need to invent new terminology to describe the diversity of for-profit enterprises, and then create a typology based on different enterprise entities, processes and effects on health.

\section{REFRAMING THE INQUIRY}

We argue that the inquiry into the effects of business on health needs to be expanded and discussed with much more nuance. Just as health is affected by 'a wide range of political, economic and social factors and processes', the understanding of the interaction between business and health must be at the interface of the social, political, commercial, corporate and other determinants of health. ${ }^{17}$ The following framework attempts to provide this nuance (see figure 2). Figure 2 was developed by the authors following review of the literature and an attempt to map out the missing elements of alternative conceptualisations.

Businesses exist in an ecosystem of political determinants, one that is characterised by dynamic relationships with social structures, including the state institutions, civil society and political economy. These social structuresthrough regulatory mechanisms, the possession of social and political capital, and consumer satisfaction-both enable and constrain business actions. These structures are in turn influenced by the actions of businesses, which we can consider under three broad limbs: (i) the entities themselves, (ii) their internal processes and (iii) their external

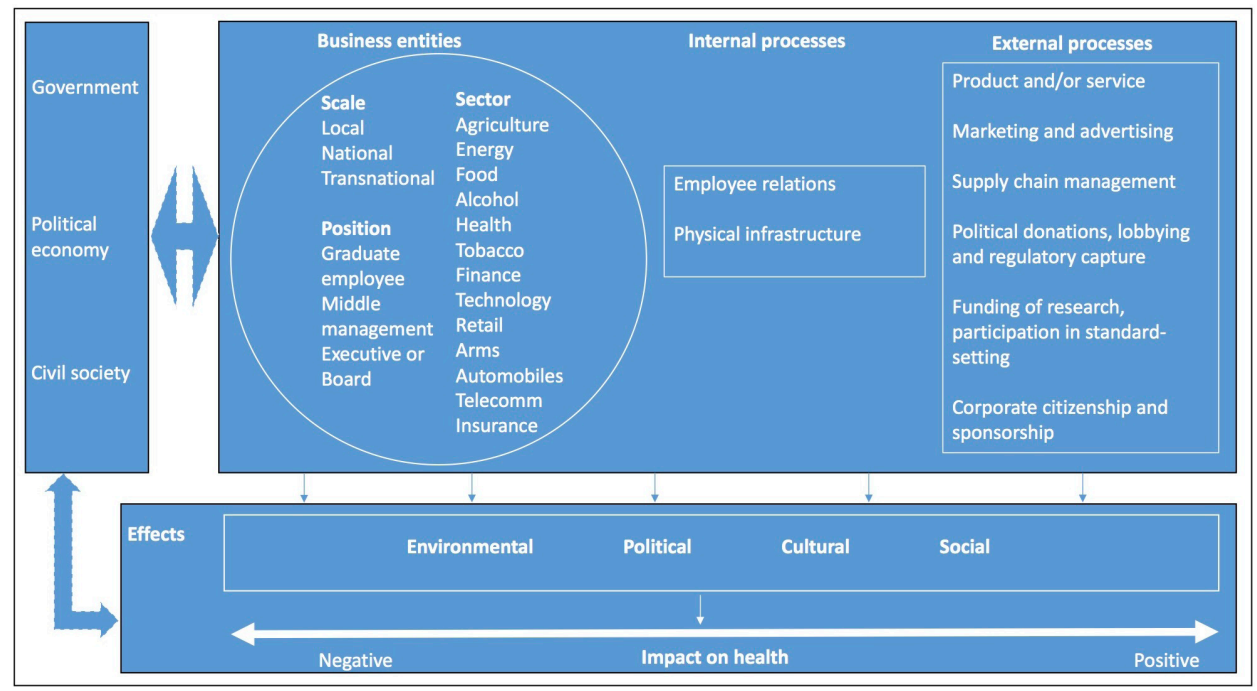

Figure 2 A reframed inquiry. 
processes. The distinction between internal and external is arbitrarily defined from the point of view of an evaluation from outside of an entity. These three elements combine to create a spectrum of effects on the various determinants of health and ultimately, health status. ${ }^{18}$

When we consider (i) business entities, there are three categories of importance: sector, scale and position. Sector refers to the type of industry (ie, agriculture, tobacco and food). While some industries are engaged in explicitly antihealth activities (eg, tobacco and gambling), the remainder-such as technology company Amazon-are characterised by significant ambiguity. Scale describes the operating jurisdiction(s) and has an important influence on a firm's direct effects on consumers, as well as their indirect influences on prevailing political and economic paradigms and on their ability to influence the marketplace and national governments. Clusters of businesses, whether in the form of a transnational corporation or industry associations, may influence the scale and influence of entities. Lastly, position attempts to distinguish between the different types of employees within a firm. It is unreasonable to hold a graduate employee and an executive to the same standard when determining responsibility for certain health impacts; Jeff Bezos, the CEO of Amazon, through virtue of his position, has greater power, and greater responsibility, to advance positive health outcomes. This reframed inquiry is inspired by insights from social theory, which posits that individuals are both influenced by and are able to influence the structures that are acting on them, and that neither reifying nor fetishising social structures, such as the 'market', is desirable. ${ }^{19}$

The category of (ii) internal processes seeks to capture two elements of business activity: employee relations and physical infrastructure. Work constitutes a significant component of people's lives, and is a major social determinant of health. The manner in which businesses employ people, provide benefits and develop a work culture will have profound effects on people's health. The physical infrastructure of the workplace is just as important. For example, are workplaces designed to avoid occupational hazards, injuries and deaths?

Lastly, when evaluating (iii) the external processes of business entities, it is important to recall that there is more to business activities than product or service delivery. Businesses are engaged in a variety of processes, including supply chain management, marketing and advertising, lobbying, political donations and corporate citizenship, the impacts of which must be evaluated. For example, what is the carbon footprint of the company and what wider environmental effects is it contributing to?

\section{CONCLUSION: TAKING THE EXPANDED INQUIRY FORWARD}

Three suggested principles should inform the consideration, critique, further development and application of our suggested approach.
First, we need to better describe and engage with the nuances and complexity of private sector activities, with new terminology allowing health professionals to stop talking about the private sector as if it were a homogenous entity. This must include better defining the types of entities (including sector, scale and position) and their myriad internal and external processes. Second, we need to consider the spectrum of effects, positive, neutral and negative, that businesses have on health. This will enable health professionals to, where justified, articulate a positive, neutral or negative role for business. Third, the specific demands on different actors and stakeholders allow a more strategic approach to 'social lobbying' and influencing key decision-makers in businesses. This could help executives, for example, to articulate to shareholders why certain public health goals have been pursued above profit margins-an example of which can be seen in the work of Tobacco Free Portfolios. Anaf $e t$ $a l$ have shown how re-conceptualisations of the nature of business and its impact can be applied practically by developing new systems for performing corporate health impact assessments. ${ }^{20}$ More needs to be done to promote nuanced approaches to the impact of business on health.

As opposed to other approaches, this analysis may increase the capacity of health advocates to contribute to feasible institutional solutions to the challenge of developing a responsible relationship between health goals and business motives. The main innovation of an expanded inquiry is to ground our evaluation in the type of organisations, operating environments and social processes-both internal and external-that generate a spectrum of health impacts. This will enable health professionals to determine which entities we should be working with (and why) and which we should not be working with (and why) (see box 1 for other advantages). Ultimately, there will be many entities that health professionals will choose to work with-noting the health downside-and many entities that we will not work with, acknowledging the possibly forgone health benefit. By reframing and expanding our inquiry into the role of business and health, we can create a more nuanced and strategic approach to identifying, advocating and delivering a healthy responsibility for the role of business in health for the 21st century.

\section{Box 1 Possible advantages of a reframed model}

1. Guidance of empirical research by extending efforts beyond the diagnosis of problems towards designing, advocating and testing positive solutions, which have been identified at prioritised intervention points.

2. Enhancing multisectoral approach by engaging individuals beyond the health sector and connecting these efforts with mature socia justice movements globally and in countries.

3. Aligns the above advantages to structural realities and to the institutional turn in political movements. 
Contributors CR and NT conceptualised the idea and contributed equally to drafting this paper. RM provided suggestions and comments to refine and extent the content. All authors edited the final draft of the paper.

Competing interests None declared.

Patient consent for publication Not required.

Provenance and peer review Not commissioned; externally peer reviewed.

Data availability statement All data relevant to the study are included in the article or uploaded as supplementary information

Open access This is an open access article distributed in accordance with the Creative Commons Attribution Non Commercial (CC BY-NC 4.0) license, which permits others to distribute, remix, adapt, build upon this work non-commercially, and license their derivative works on different terms, provided the original work is properly cited, appropriate credit is given, any changes made indicated, and the use is non-commercial. See: http://creativecommons.org/licenses/by-nc/4.0/.

\section{REFERENCES}

1. Tracer Z. Amazon-Berkshire-JPMorgan Health Venture Takes Aim at Middlemen - Bloomberg [Internet]. Bloomberg, 2018. Available: https://www.bloomberg.com/news/articles/2018-06-24/amazonberkshire-jpmorgan-health-venture-takes-aim-at-middlemen [Accessed cited 29 Nov 2018].

2. Holmes D. All change for the NHS in England as legislation takes effect. The Lancet 2013;381:1169-70.

3. Glenza J. Ex-UN chief Ban Ki-moon says US healthcare system is "morally wrong." The Guardian [Internet], 2018. Available: https:// www.theguardian.com/us-news/2018/sep/25/ex-un-chief-bankioon-says-us-healthcare-system-is-morally-wrong [Accessed cited 29 Nov 2018].

4. Sweney M. Amazon halved Corporation Tax bill despite UK profits tripling. the guardian, 2018. Available: https://www.theguardian.com/ technology/2018/aug/02/amazon-halved-uk-corporation-tax-bill-to45m-last-year [Accessed cited 29 Nov 2018].

5. Jones $\mathrm{O}$. Tax avoidance may be legal but it's bankrupting our social order | Owen Jones. The Guardian, 2017. Available: https://www. theguardian.com/commentisfree/2017/nov/07/paradise-papersbankrupt-social-order-tax-avoiders [Accessed cited 29 Nov 2018].

6. Millar JS. The corporate determinants of health: how big business affects our health, and the need for government action! Can J Public Health 2013;104:e327-9.

7. Kickbusch I, Allen L, Franz C. The commercial determinants of health. Lancet Glob Health 2016;4:e895-6.

8. Babic M, Fichtner J, Heemskerk EM. States versus corporations: rethinking the power of business in international politics. The International Spectator 2017;52:20-43.

9. McKee M, Stuckler D. Revisiting the corporate and commercial determinants of health. Am J Public Health 2018;108:1167-70.

10. Demaio A, Marshall R. Social lobbying: a call to arms for public health. The Lancet 2018;391:1558-9.

11. Hodgson H. Global health Watch 5: an alternative World Health report. Medicine, Conflict and Survival 2017;33:323-5.

12. Beaubien J. "Beer Girls" Break Up Global Fund/Heineken Party [Internet]. National Public Radio, 2018. Available: https://www.npr. org/sections/goatsandsoda/2018/03/30/598270449/beer-girlsbreak-up-global-fund-heineken-party [Accessed cited 29 Nov 2018].

13. Daube M, Moodie R, McKee M. Towards a smoke-free world? Philip Morris international's new Foundation is not credible. The Lancet 2017;390:1722-4.

14. Buse K, Waxman A. Public-private health partnerships: a strategy for who. Bull World Health Organ 2001;79:748-54.

15. Sixty-Ninth World Health Assembly. Framework of engagement with non-State actors [Internet]. World Health Organisation, 2016. Available: http://www.who.int/about/collaborations/non-state-actors/ A69_R10-FENSA-en.pdf [Accessed cited 29 Nov 2018].

16. Miller D, Harkins C, strategy C. Corporate strategy, corporate capture: food and alcohol industry lobbying and public health. Crit Soc Policy 2010;30:564-89.

17. Kickbusch I. Addressing the interface of the political and commercial determinants of health. Health Promot Int 2012;27:427-8.

18. Rasanathan K. 10 years after the Commission on social determinants of health: social injustice is still killing on a grand scale. The Lancet 2018;392:1176-7.

19. Giddens A. Agency, structure. in: central problems in social theory. Springer, 1979: 49-95.

20. Anaf J, Baum FE, Fisher M, et al. Assessing the health impact of transnational corporations: a case study on McDonald's Australia. Global Health 2017;13. 